\title{
Water Security through Institutional Resilience in the transboundary Paso del Norte region
}

\author{
Luzma Fabiola Nava, Ph.D., A.M. ASCE*
}

\begin{abstract}
The Paso del Norte $(\mathrm{PdN})$ region is one of the most environmental damaged, prolific in irrigation, hydrological developed area in the Rio Grande/Bravo basin (RGB). With an average rainfall of about $150 \mathrm{~mm}$ of rain and increasing evaporation rates, crops such as maize, alfalfa, pecans, chili, and cotton are growing in this semi-arid region. Climate change is expected to affect the quality of aquatic environments while accentuating sustained drought and water scarcity. Laws and regulations governing water in the $\mathrm{PdN}$ region need to be adapted to this reality. Water security in the PdN region is a binational challenge. Institutions, 'the rules of the game', have to be well thought-out, clearly targeted and made context specific. How do institutions governing water resources absorb changes, cope with major climatic challenges, and adapt to new conditions and imperatives? Stakeholders from the PdN region provide insights to foster water security and enable regional flexibility on the existing ensemble of policy processes. Building institutional resilience is paramount in responding to new imperatives in the PdN.
\end{abstract}

Keywords: Water Security; U.S. - Mexico, Transboundary Waters; Institutional Resilience; Adaptation; Political Willingness.

\footnotetext{
${ }^{*}$ Guest Research Scholar

International Institute for Applied Systems Analysis (IIASA), Laxenburg A-2361, Austria;

email: nava@iiasa.ac.at
} 
"Deserts are unique places because the plants and animals living there have to be strong and uniquely adapted to survive. The people who've lived here, now and going back thousands of years, had to adapt to this environment, and in doing so they developed unique customs and technologies with a particular kind of resiliency." Personal communication with a stakeholder. October-November2015.

\section{INTRODUCTION}

The United States (U.S.) and Mexico share a nearly $3200 \mathrm{~km}$ long border that crosses three river basins: the Colorado River (CR), the Tijuana River (TR), and the Rio Grande/Bravo (RGB) as shown in Figure 1. This paper focuses on the surface water resources of the RGB (hereinafter the term water refers to surface water resources unless otherwise specified). The RGB is longest of these rivers and forms an international boundary of $2034 \mathrm{~km}$. The Rio Grande, as it is known in the United states (U. S.), or the Río Bravo, as it is called in Mexico, is the 20th largest river in the world, with a total length of $3059 \mathrm{~km}$. It carries less water than rivers of similar size because it runs through arid areas for most of its length (the mean flow is $25 \mathrm{~m}^{3} / \mathrm{s}$ at Matamoros, 1955-2006; by comparison, the Danube, River, a river of similar length, has a mean flow of $6486 \mathrm{~m}^{3} / \mathrm{s}$ just before the delta). Higher precipitation only characterizes its headwater (>800 $\mathrm{mm}$ ) and mouth regions $(650 \mathrm{~mm})$. The river basin covers an area of $924,300 \mathrm{~km}^{2}$, divided almost in half between the two countries (Nava et al. 2016).

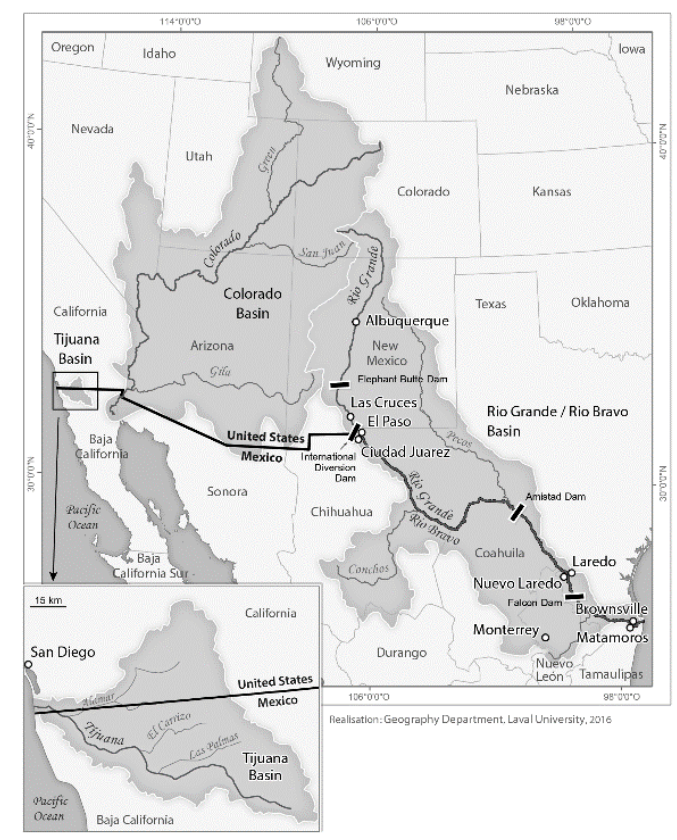

Figure 1. The shared rivers between the U. S. and Mexico (Nava et al. 2016). 
The water of the RGB is allocated within a binational legal framework that distributes water resources, sets extractions and diversions, and sustains political boundaries between the U.S. and Mexico. Allocations to each country are based on an estimate of the basin's hydrology at the time decisions were made. These have remained unchanged despite a substantial increase in water demands, multiple coexisting water users, and unmet environmental and sustainability needs. Limited water resources in the context of an arid climate and related environmental vulnerabilities invite competition for water resources at the watershed scale, and across and along the border (Nava et al. 2016).

This paper answers the following question: How do institutions governing water resources absorb changes, cope with major climatic challenges, and adapt to new conditions and imperatives? Posing this question directs attention to the existing opportunities to build institutional resilience by integrating stakeholders' insights, and their capacity and willingness to participate in managing

natural resources and solve common problems. A preliminary set of policy recommendations highlights institutional resilience depends on political will and stakeholders' insights. In order to illustrate this potential, the focus will be given to the transboundary Paso del Norte (PdN) region.

\section{BACKGROUND}

The Treaty between the United States of America and the United Mexican States relating to the utilization of the waters of the Colorado and Tijuana Rivers, and of the Rio Grande (Rio Bravo) known widely as the 1944 Water Treaty was signed in 1944. It was ratified by each country in 1945. The 1944 Treaty aims to obtain the most complete and satisfactory utilization of shared waters based on the equitable distribution between the two countries of the waters of shared river systems. Under the 1944 Treaty, the International Boundary Commission (IBC), established in 1889 to rectify and maintain the riparian boundary of the Rio Grande and Colorado Rivers, became the International Boundary and Water Commission (IBWC, hereinafter called the Commission), with specific mandates on shared water resources. The 1944 Water Treaty establishes the Commission's authority as an international body and endows it with considerable flexibility in addressing existing and emerging issues through the Minute process (Nava et al. 2016). 


\section{Case-study: The Transboundary Paso del Norte Region}

The PdN emblematizes an important regional focus of attention. The PdN region is located right at the mid-point of the U.S.-Mexico border and the RGB basin. The region extends approximately $547 \mathrm{~km}$ along the RGB from Elephant Butte Reservoir in southern New Mexico (NM) to the confluence of the Rio Conchos in Presidio County, Texas (Tx). The region, as shown in Figure 2, drains some areas in the U.S. states of NM, and Tx, and Chihuahua (Ch) in Mexico.

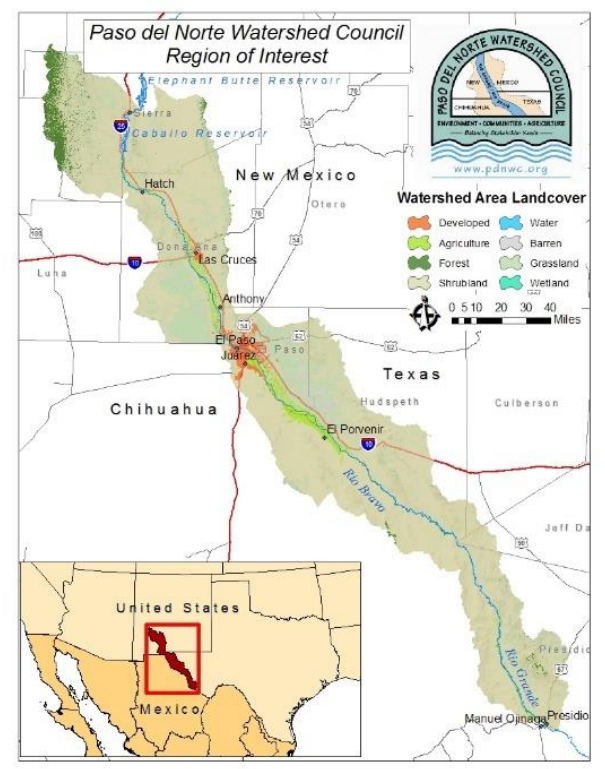

Figure 2. The Paso del Norte region Available at: http://www.pdnwc.org/

With a population of 2.5 million inhabitants, the PdN constitutes one of the largest international cross border regions in the world and the largest metropolitan area on the border (OECD 2010). The cities of Las Cruces (NM), El Paso (Tx), and Ciudad Juarez (Ch) are the main metropolitan areas in this transboundary region, and both surface and groundwater feed their demands. The region is mainly sustained by the RGB. However, for municipal and industrial water supply, Las Cruces takes water from the Mesilla Bolson; El Paso uses water from the Hueco Bolson, the Mesilla; and Ciudad Juarez takes water from the Hueco Bolson. El Paso and Ciudad Juarez represent the largest population centres in the basin where the main challenge is fulfilling the municipal water needs (Kelly 2002, Parcher et al. 2010). 
The PdN region is one of the most irrigation intensive and environmentally damaged areas in the RGB (Riley 1995). With an average rainfall of about 150mm of rain and increasing evaporation rates, crops such as maize, alfalfa, pecans, chili, and cotton are growing in this semi-arid region. Climate change is expected to have consequences in the water cycle by reducing surface flows and aquifer recharge rates. It is also expected to affect the quality of aquatic environments and accentuate sustained drought and water scarcity. This regional environmental damage translates into water quantity and water quality issues. Water quality degradation is imperiling and stressing the delicate ecosystems supported by the river. Issues such as salinity, bacteria, ammonia, chlorophyll, and nitrate; residual pharmaceuticals in wastewater; and lack of green corridors and loss of biodiversity are accentuating impoverishment of natural ecosystems (Kelly 2002, Parcher, et al. 2010, USBOR 2011, Texas Clean Rivers Program 2016).

A greater likelihood of a water crisis is occurring in the $\mathrm{PdN}$ region. Water is scarce, and competition for water resources is intensifying. Agricultural water use is relatively constant; increased water demand is being driven by urban growth; and intensive human use of water is impoverishing natural ecosystems. The PdN region continues to experience rapid population growth despite its diminishing water resources. Institutional fragmentation and hydrological organization in this binational and tri-state region prevents water managers' preparedness for upcoming climate challenges as well as the development of adaptive management strategies (Nava and Sandoval-Solis 2014). Furthermore, stakeholders' competing and conflicting interests tend to accentuate the unsustainable extraction and use of the region water resources, and therefore the design of policies. Laws and regulations governing water in the PdN region need to adapt to this reality. Failure to adapt will only jeopardize the satisfaction of the regional needs in a sustainable manner, leading to water crises.

\section{METHODOLOGY}

\section{Institutional Resilience}

Institutions determine 'the rules of the game' (Commons 1934, North 1990, Veblen 1909). Water security in the arid $\mathrm{PdN}$ region is a binational challenge requiring resilience in institutions by means of political will and stakeholders' insights. Institutions have to be well thought-out, clearly 
targeted and made context specific by adopting new strategies to manage risk. For this purpose, resilience is an important notion. The Oxford English Dictionary defines resilience as the ability to spring back into shape; a certain degree of elasticity (Oxford Dictionaries, 2016). The term can be conceptualized in many ways. Here, it is about how institutions governing water resources may absorb changes, cope with major climatic challenges, and adapt to new conditions and imperatives. In this context, applying the notion of resilience to management and governance helps to understand how institutional frameworks adapt and prepare for uncertain futures.

Institutions can no longer be perceived of as isolated, independent, and perennial from the socialecological context in which they operate, since they are in constant interaction to manage environmental, social and economic domains. A resilient institution translates into a flexible framework for adapting to the current climate vulnerabilities threatening water resources. It also represents a strategic opportunity to move forward in a new direction to sustain and secure water. Building institutional resilience by means of enabling regional openness and flexibility of the existing ensemble of rules and policy processes is paramount to respond to new imperatives (Boyd 2012; Folke 2006, Handmer and Dovers 1996, Pahl-Wostl 2007, Pahl-Wostl et al. 2007). Stakeholders from the PdN region provide insights into what they wish could done to enable institutional resilience and foster regional water security.

\section{Qualitative methods}

This research employs an interdisciplinary and qualitative approach to problem identification and analysis. Our qualitative approach is composed of various methodological tools, including casestudy analysis, collection of documents, and field work and semi-structured interviews. The PdN round of field work consists on the application of a questionnaire (40 multiple-choice questions, and 10 open-ended questions) to gain information on water resources management and sustainable practices. A total of 23 interviews were conducted between October-November 2015. Taking into account the location of the respondents, the questionnaire was applied on the basis of their availability, in places that respondents preferred, either their workplace or a public place. In situations where travel was difficult, the questionnaire was sent by the internet. In some cases, answers to open-ended questions were recorded with a digital recorder, and transcribed with 
Nvivo9 and Nvivo10 software. We used NVivo 10 to do qualitative content analysis (Nava Jimenez 2015). For ethical reasons, we ensure the confidentiality of the participants. However, more specific details on the stakeholders' profile and questionnaire process can be found in Nava et al 2016.

\section{RESULTS AND DISCUSION}

All those questioned in this assessment agreed on the importance of enhanced water resources management to deal with vulnerability in an arid context (Figure 3). Stakeholders' insights have been systematized in three solutions-options reflecting their main visions to solve common problems and foster water security in the PdN region.

1. Living in an arid context translates into a set of challenges, and a region of opportunities:

a. A set of challenges:

i. Water is not an abundant available resource,

ii. Droughts may become more frequent and severe in nature,

iii. Water resources competition will likely increase, and

iv. Potential risks of conflicts over water supplies and access to water.

b. A region of opportunities:

i. The capacities of plants and animals to adapt and survive,

ii. The determination and willingness of people to adapt and survive,

iii. The development of unique customs, procedures, and technologies to address difficulties in this region, and

iv. The potential to adapt water allocation and management approaches, and to conform to current and future water issues.

2. There is a great need to:

a. Strengthen communication and collaboration among all of stakeholders and related water agencies;

b. Provide environmental education across the regional river basin; 
c. Manage surface and groundwater jointly; and

d. Update water allocation agreements between the parties.

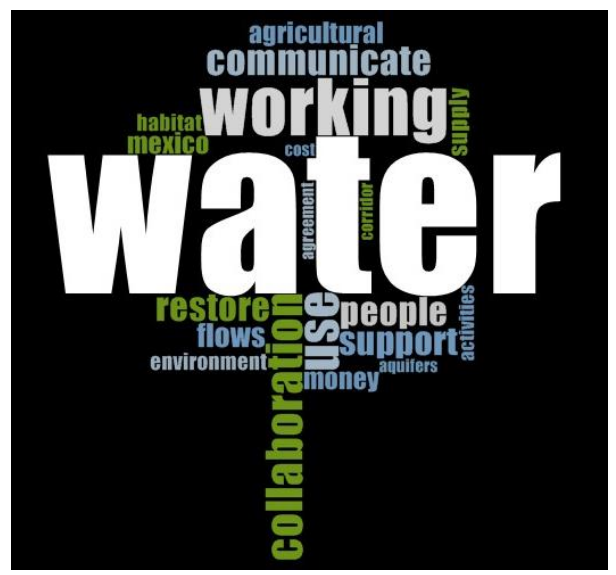

Figure 3. Qualitative results on stakeholders' insights

3. At the moment, the only binational mechanism available to solve a water-related problem and secure water in the $\mathrm{PdN}$ region is the Minute process.

a. The Minute process represents the institutional instrument to frame stakeholders' concerns related to water quantity and water quality issues.

\section{CONCLUSION AND POLICY RECOMMENDATIONS}

North American countries are known for their water wealth. A total of fifteen surface water sources are shared along the border areas. Canada and the U.S. share twelve rivers and lakes, while the border between the U.S. and Mexico is drained by three river basins. By means of the International Joint Commission (IJC), Canada and the U.S. cooperate to manage their waters wisely and to protect them for the benefit of its citizens and future generations. For their part, the U.S. and Mexico cooperate through the IBWC to solve issues that arise during the application of binational treaties regarding national ownership of waters, sanitation, water quality, and flood control in the border region.

The binational capacity to prevent a water crisis and secure water in the transboundary PdN region hinges on the ability to create resilient water institutions by means of recognizing the need to plan 
for the unexpected, to involve stakeholders, and to learn from and replicate successful initiatives. The U.S.-Canada International Watersheds Initiative (IWI) is a neighboring experience from which the U.S. and Mexico can learn new practices to address water issues and secure through an integrated ecosystem approach, stakeholders' involvement, and iterative assessment of the effectiveness of decisions over time (IJC 2016). The IBWC is called upon to play a major role in this process. Stakeholders from the PdN region provide insights into what they wish to be done to enable institutional resilience and foster regional water security.

Having said that, the main argument guiding our preliminary set of policy recommendations to foster water security and build water resilient institutions in the $\mathrm{PdN}$ is that:

The Minute Process is the binational mechanism allowing flexibility to the 1944 Water Treaty by enabling a common interpretation on a water-boundary issue (Nava et al. 2016).

The 1944 Water Treaty is the cornerstone for managing shared waters crossing the U.S.-Mexico border. Its importance is due to fixing the distribution of water resources and establishing the Minute process as the binational mechanism allowing for flexibility to address new circumstances. This process allows to update the Treaty on an ad hoc basis. Learning from the International Watersheds Initiative (IJC, 2016), a new Minute for Binational Water Security through Institutional Resilience in the transboundary Paso del Norte region may be jointly agreed on the following six points:

1. The acknowledgement that the transboundary Paso del Norte represents a regional watershed ecosystem integrated by local communities and flora and fauna resources.

a. Practicing an ecosystem approach to manage water, living resources, and land may promote conservation and sustainable water security.

2. The recognition that managing water scare resources in an arid context requires the development of regional techniques and procedures to optimally accentuate their benefits.

a. In this case, it is a responsibility shared by the signatory countries to facilitate the necessary means to achieve this requirement. 
3. The establishment of an inclusive process to address the interests from organized stakeholders and environmental groups.

a. The creation of an exploratory Water Task Force to obtain recommendations from regional stakeholders, such as in the Tijuana River Basin, the Lower Colorado River, and the Colorado River Delta is crucial (Nava et al. 2016).

4. The exploration of a sustainable water use and allocation system for the comprehensive sustainability of the region.

a. Water resources may be reallocated from upstream to downstream users, from one use to another, and vice versa, in times of drought and abundance of water.

5. Both, the U.S. and Mexico are aware of the issues influencing regional transboundary water quality and water flows.

a. Sustaining water flows may be hydrologic and economic feasible with the region.

6. The effectiveness of decisions over time will lead to water resilient institutions ensuring water security in the region.

a. Institutional resilience may be an ongoing process as stakeholder needs and concerns are evolving. Iterative adaptation of institutions may secure water in a sustained manner.

The Minute process makes of the 1944 Water Treaty a resilient institution; it enables the Treaty to respond to emerging issues and design new policy initiatives. Stakeholders from the transboundary Paso del Norte may advocate for a binational zest for political willingness to secure water in the region. They may call upon the Commission to play the role of chief negotiator in this process.

ACKNOWLEDGEMENTS. The author would like to thank all anonymous stakeholders and experts for their willingness to participate in the interviews by providing meaningful insights.

\section{REFERENCES}

Boyd, E. (2012). "Adapting to global climate change: evaluating resilience in two networked public institutions", Adapting Institutions: Governance, Complexity and Social-Ecological 
Resilience, ed. Emily Boyd and Carl Folke. Published by Cambridge University Press, p. 240244.

Commons, J. R. (1934). Institutional Economics-Its Place in Political Economy. New York: Macmillan.

Folke, C. (2006). Resilience: the emergence of a perspective for social-ecological systems analyses. Global Environmental Change, 16, 253-267.

Handmer W. and Dovers, S. (1996). A typology of resilience: Rethinking institutions for sustainable development Industrial and Environmental Crisis Quarterly, 9 (4) (1996), pp. 482511.

IJC (2016). International Joint Commission. International Watersheds Initiative. Available online: http://www.ijc.org/en_/IWI/Principles (Accessed on August 21, 2016).

Kelly, M. E. 2002.Water Management in the binational Texas/Mexico Rio Grande/Rio Bravo Basin. Yale For. Environ. Stud. Bull., 115, 134.

Nava, L. F., et al. (2016). "Existing opportunities to adapt the Rio Grande/Bravo Basin Water Resources Allocation Framework", Water, 8(7), 291; doi:10.3390/w8070291.

Nava, L.F. and Sandoval-Solis, S. (2014). Multi-tiered Governance of the Rio Grande/Bravo Basin: The fragmented water resources management model of the United States and Mexico. International Journal of Water Governance, 2, 85-106.

Nava Jiménez, L.F. (2015). La Gouvernance du Bassin Versant du Rio Grande/Río Bravo et les Principes du Développement Durable; Université Laval: Québec City, QC, Canada.

North, D. C. (1990). Institutions, Institutional Change, and Economic Performance. Cambridge: Cambridge University Press.

OECD (2010). Organisation for Economic Cooperation and Development. Higher Education in Regional Development: Paso del Norte Region, Mexico and the United States. Available online: https://www.oecd.org/mexico/45820961.pdf (accessed on 25 July 2016).

Oxford Dictionaries. Resilience. Available online:

http://www.oxforddictionaries.com/definition/english/resilience (accessed 4 May 2016).

Pahl-Wostl, C. (2007). Transitions towards adaptive management of water facing climate and global change. Water Resources Management, 21, 49-62.

Pahl-Wostl, C., Sendzimir, J., Jeffrey, P., et al. (2007). Managing change toward adaptive water management through social learning. Ecology and Society, 12(2), 30. www.ecologyandsociety.org/vol12/iss $2 / \operatorname{art} 30$

Parcher, J. et al. (2010). A descriptive overview of the Rio Grande-Rio Bravo Watershed. Journal of Transboundary Water Resources, 1, 159-177.

Riley, C. L. (1995). Rio del Norte: People of the Upper Rio Grande From Earliest Times to the Pueblo Revolt. Salt Lake City: University of Utah Press, p. 119-125. UTEP. An Economic Development Strategy for the Sustainable Use of Water in the Paso del Norte Region. (No longer) available online www.utep.edu/rio/Executive_Summary.htm (accessed on 12 February 2008).

Texas Clean Rivers Program (2016). 2013 Rio Grande Basin_-Summary Report. Available online: http://www.ibwc.state.gov/CRP/documents/USIBWC_Rio_Grande_Basin_Summary_Report 082613.pdf (accessed on 22 March 2016).

USBOR, Bureau of Reclamation (2011). SECURE Water Act Section 9503(c) - Reclamation Climate Change and Water, Report to Congress, 2011. 
Veblen, T. B. (1899). The Theory of the Leisure Class: An Economic Study in the Evolution of Institutions. New York: Macmillan. 